\title{
The brain-derived neurotrophic factor (BDNF) val66met polymorphism differentially affects performance on subscales of the Wechsler Memory Scale - Third Edition (WMS-III)
}

Yvette N. Lamb*, Christopher S. Thompson, Nicole S. McKay, Karen E. Waldie and lan J. Kirk

School of Psychology, Faculty of Science, The University of Auckland, Auckland, New Zealand
OPEN ACCESS

Edited by:

Eddy J. Davelaar

Birkbeck, University of London, UK

Reviewed by:

Darlene A. Kertes,

University of Florida, USA

Christian Beste,

Ruhr Universität Bochum, Germany

*Correspondence:

Yvette N. Lamb,

School of Psychology, Faculty

of Science, The University

of Auckland, Private Bag 92019,

Auckland 1142, New Zealand

yvette.lamb@auckland.ac.nz

Specialty section:

This article was submitted to

Cognitive Science,

a section of the journal

Frontiers in Psychology

Received: 05 February 2015

Accepted: 30 July 2015

Published: 17 August 2015

Citation:

Lamb YN, Thompson CS, McKay NS,

Waldie KE and Kirk IJ (2015)

The brain-derived neurotrophic factor (BDNF) val66met polymorphism differentially affects performance on subscales of the Wechsler Memory Scale - Third Edition (WMS-III).

Front. Psychol. 6:1212. doi: 10.3389/fpsyg.2015.01212
Single nucleotide polymorphisms in the brain-derived neurotrophic factor (BDNF) gene and the catechol-O-methyltransferase (COMT) gene influence brain structure and function, as well as cognitive abilities. They are most influential in the hippocampus and prefrontal cortex (PFC), respectively. Recall and recognition are forms of memory proposed to have different neural substrates, with recall having a greater dependence on the PFC and hippocampus. This study aimed to determine whether the BDNF val66 met or COMT val ${ }^{158}$ met polymorphisms differentially affect recall and recognition, and whether these polymorphisms interact. A sample of 100 healthy adults was assessed on recall and familiarity-based recognition using the Faces and Family Pictures subscales of the Wechsler Memory Scale - Third Edition (WMS-III). COMT genotype did not affect performance on either task. The BDNF polymorphism (i.e., met carriers relative to val homozygotes) was associated with poorer recall ability, while not influencing recognition. Combining subscale scores in memory tests such as the WMS might obscure gene effects. Our results demonstrate the importance of distinguishing between recall and familiarity-based recognition in neurogenetics research.

Keywords: neurogenetics, BDNF, memory, recall, recognition

\section{Introduction}

Individual differences in the memory ability of healthy individuals are ubiquitous, readily observed both within the laboratory and without. A single nucleotide polymorphism (SNP) found in the gene coding for brain-derived neurotrophic factor (BDNF) has been implicated in variation in mnemonic ability (e.g., Egan et al., 2003; Hariri et al., 2003). Similarly, individual differences in a range of cognitive skills have been attributed partly to a SNP in the gene coding for catecholO-methyltransferase (COMT; e.g., Egan et al., 2001; de Frias et al., 2004). The present study investigated the effects of the $B D N F \mathrm{val}^{66}$ met and $C O M T \mathrm{val}^{158}$ met polymorphisms on recall and recognition, two neurally dissociable forms of memory.

When researching the potential genetic correlates of memory performance, it is necessary to distinguish between forms of memory. Previous research in this area has often used memory 
scores that collapse across different forms of memory. However, it is probable that forms of memory are influenced by unique clusters of genes (Nilsson, 2000). One major qualitative division of memory exists between recall and familiarity judgments (Mandler, 1980, 2008). Familiarity-based memory, a component of recognition, is the capacity to judge the extent to which a stimulus has previously occurred. This ability does not necessitate the retrieval of specific information concerning the context in which the previous encounters took place (Perfect et al., 1996). Recollection, on the other hand, entails the retrieval of precise identifying characteristics of the stimulus, or contextual information such as concepts with which the stimulus was previously associated.

Aggleton and Brown (1999) proposed that these memory functions are the products of two limbic loops that are, to a large extent, functionally independent. The recall of episodic or episodic-like information is achieved by a network of structures involving the hippocampus and the anterior thalamic complex. Familiarity judgments were proposed to be accomplished by a second network which instead incorporates the perirhinal cortex and the mediodorsal thalamus. Animal studies (e.g., Morris et al., 1982; Meunier et al., 1993; Steele and Rawlins, 1993; Duva et al., 1997; Bussey et al., 1999) and neuroimaging studies of humans (e.g., Squire et al., 1992; Schacter et al., 1996; Kirk et al., 2004; Ryan et al., 2008; Kafkas and Montaldi, 2012) have provided empirical support for Aggleton and Brown's hypotheses, although there is some recent evidence that the mediodorsal thalamus plays a role in recall (e.g., Pergola et al., 2012, 2013).

While most aspects of Aggleton and Brown's (1999) model have received considerable support, one criticism has been that Aggleton and Brown (1999) do not fully acknowledge the particular importance of the prefrontal cortex (PFC) in recall (Knowlton, 1999; Parker, 1999). A review by Davidson et al. (2006) suggests that the PFC may be more crucial for recall than recognition, although further research into this is necessary. The greater importance of the PFC in recall is consistent with the role this region is thought to play in binding diverse pieces of information together (Fernández and Tendolkar, 2001). From research implicating frontal and medial temporal formations in memory processes, it follows that genes affecting the structure and function of these regions could also influence memory performance.

Part of the neurotrophin family, BDNF is a small, dimeric signaling protein (Lessmann et al., 2003). BDNF promotes neuronal growth and differentiation whilst the peripheral and central nervous systems develop (Poo, 2001; Huang and Reichardt, 2003). Although the functions of BDNF in the adult brain are less understood (Cunha et al., 2010), BDNF has been found to encourage neurogenesis in the mature dentate gyrus (Sairanen et al., 2005; Scharfman et al., 2005; Thakker-Varia et al., 2014) and striatum (Mohapel et al., 2005). BDNF also appears to play a vital role in long-term potentiation (LTP; Poo, 2001; Panja and Bramham, 2014), the long-lasting enhancement of synaptic efficacy that is thought to underlie memory and learning (Bliss and Collingridge, 1993; Cooke and Bliss, 2006). Egan et al. (2003) proposed that it is through the role of BDNF in LTP that BDNF secretion impacts memory and learning (see Lamb et al., 2014 for a recent review).

The BDNF $\mathrm{val}^{66}$ met polymorphism produces a nonconservative substitution of a valine with a methionine at codon 66 of this gene (Egan et al., 2003; Chen et al., 2004). In a population of European ancestry, $64 \%$ of individuals are val homozygotes (val/val), another $3 \%$ are met homozygotes (met/met), and the $34 \%$ that remain are heterozygotes (val/met; HapMap-CEU). The presence of the met allele has been associated with decreased activity-dependent secretion of BDNF and abnormal intracellular trafficking of the protein (Egan et al., 2003). In accordance with BDNF expression being maximal in the hippocampus (Murer et al., 2001), three meta-analyses have reported that the met allele is associated with lower hippocampal volume (Hajek et al., 2012; Kambeitz et al., 2012; Molendijk et al., 2012). It should, however, be noted that a later meta-analysis by Harrisberger et al. (2014) found no evidence of BDNF genotype affecting hippocampal volume, suggesting previous effects may have been overestimated.

Hariri et al. (2003) demonstrated that individuals carrying a met allele show less hippocampal activation during memory encoding and retrieval than val homozygotes, which may reflect impaired synaptic events in the met carriers. A weaker memory trace may be formed, thus accounting for their poorer subsequent performance on the hippocampal-dependent memory task. While the cumulative literature does suggest that the met allele is detrimental to memory (see Kambeitz et al., 2012 for a meta-analysis), a number of empirical studies have not detected an association between genotype and memory performance (e.g., Hansell et al., 2007; van Wingen et al., 2010). This inconsistency may in part reflect differences in the forms of memory assessed and the extent to which they are dependent on the hippocampus.

As with the neurotrophins, neurotransmitters and the proteins that regulate them are integral to neurodevelopment and cognition. The metabolism of released dopamine is catalyzed by COMT, with the degradation decreasing levels of this neurotransmitter within the synapse (Egan et al., 2001). Insufficient dopamine has been implicated in deficits across a range of cognitive domains (Nieoullon, 2002), including memory (e.g., Brozoski et al., 1979; Cai and Arnsten, 1997). Interestingly, excessive dopaminergic activity appears to also be detrimental for the memory functions of the PFC (e.g., Cai and Arnsten, 1997; Zahrt et al., 1997). Xu et al. (2009) demonstrated that when dopamine is significantly increased in mice, the induction of LTP in the PFC is eroded rather than facilitated.

The activity and thermal stability of the COMT enzyme are influenced by a common SNP located on the coding region of the COMT gene (Lotta et al., 1995; Lachman et al., 1996). This $\mathrm{val}^{158}$ met polymorphism involves a valine being switched for a methionine. In a European population, $29 \%$ are homozygous for the val allele (val/val), $25 \%$ are homozygous for the met allele (met/met) and the $46 \%$ are heterozygotes (val/met; HapMap$\mathrm{CEU})$. At body temperature, the met allele is associated with almost four times more COMT activity than the val allele (Lachman et al., 1996). Met homozygotes would thus be expected to have slower dopamine inactivation than val homozygotes. The 
alleles appear to be codominant, with heterozygotes displaying an intermediate phenotype (Chen et al., 2004).

COMT genotype has been found to affect gray matter levels in the hippocampus and dorsolateral PFC (Honea et al., 2009). Functional differences have also been observed. In an fMRI study by Egan et al. (2001), PFC blood oxygenation level dependent (BOLD) response during a working memory task differed as a function of genotype. The greatest BOLD response was seen in the val homozygotes and may indicate a less efficient system. This differential PFC response has been replicated in a number of later studies (e.g., Mattay et al., 2003; Meyer-Lindenberg et al., 2006; Jasper et al., 2015). As there are few dopamine transporters in the PFC, variation in COMT function could be particularly influential on activity in this region (McIntosh et al., 2007).

COMT genotype has been demonstrated to predict variation in executive function (e.g., Egan et al., 2001; Malhotra et al., 2002; Mitaki et al., 2013) and processing speed (e.g., Bilder et al., 2002), with the met allele typically being associated with superior performance (although a meta-analysis by Barnett et al., 2008 suggests genotypic effects may be smaller than initially thought). A number of studies have reported met homozygotes to have an advantage on memory tasks when compared to val carriers (e.g., de Frias et al., 2004; Enoch et al., 2009; Raz et al., 2009). de Frias et al. (2004) found that when episodic memory was broken down into its elements of recall and recognition, a significant difference between genotypes was only present for the recall component. This differential effect demonstrates that the polymorphism could have some degree of memory specificity, possibly driven by the relative involvement of the PFC.

The present study aimed to examine both recall and recognition performance in the same group of participants, to determine (1) whether the $B D N F$ val $^{66}$ met polymorphism differentially influences performance on recall and recognition tasks; (2) whether the COMT val $^{158}$ met polymorphism differentially influences performance on recall and recognition tasks; and (3) whether the BDNF val ${ }^{66}$ met and COMT val ${ }^{158}$ met polymorphism interact to influence either recall or recognition performance. Based on the particular influence of the $B D N F$ $\mathrm{val}^{66}$ met polymorphism on the hippocampus and the specific dependency of recall on the hippocampus, it was hypothesized that the $B D N F$ polymorphism would influence recall but not familiarity-based recognition. On the recall task, val homozygotes were expected to outperform those with the met allele, thus replicating the results of past research on hippocampal-dependent memory (e.g., Egan et al., 2003; Hariri et al., 2003). As the influence of the COMT val ${ }^{158}$ met polymorphism appears to be highest in the PFC, COMT genotype was also predicted to solely affect performance on the recall task. On this task, met homozygotes were expected to perform better than individuals with the val allele, replicating de Frias et al. (2004).

Brain-derived neurotrophic factor plays a pivotal role in the development of dopaminergic-related systems (Zhou et al., 1994), while COMT levels affect the structure of frontal and limbic regions (e.g., Honea et al., 2009). Furthermore, BDNF (Poo, 2001) and COMT (Jacobsen et al., 2010) both influence forms of LTP and a study by Witte et al. (2012) has noted that the
$B D N F$ and COMT polymorphisms interact to impact on cortical plasticity. A BDNF and COMT interaction has also been recently reported for immediate recall in older adults (Stuart et al., 2014). Consequently, it was hypothesized that an interaction between the $B D N F \mathrm{val}^{66}$ met and COMT val ${ }^{158}$ met polymorphisms might be found for recall performance.

\section{Materials and Methods}

\section{Participants}

A sample of 100 healthy university students aged between 18 and 42 years $(M=23.3, \mathrm{SD}=4.0)$ participated in this study. Of these participants, 64 were female. Participants had either normal or corrected-to-normal vision. All participants gave their informed consent for inclusion in this study and the University of Auckland Human Subjects Ethics Committee approved all study procedures.

\section{Genotyping DNA Collection}

Participants were asked to give a small blood sample or saliva sample. Blood sample collection was performed with sterile procedures. Saliva samples were collected using OrageneDNA Self Collection kits in a manner consistent with the manufacturer's instructions.

\section{DNA Extraction}

DNA was extracted from the blood samples following the method outlined by Miller et al. (1988) and from the saliva samples following the method given by Nishita et al. (2009). All resultant DNA samples were resuspended in Tris-EDTA buffer and were quantified used Nanodrop ND-1000 1-position spectrophotometer (Thermo Scientific).

\section{DNA Amplification}

The DNA samples were all diluted to $50 \mathrm{ng} / \mu \mathrm{L}$. A modified version of the method described by Erickson et al. (2008) was used for the DNA amplification. Amplification was carried out on the 113 bp polymorphic BDNF fragment, using the primers BDNF-F 5-GAG GCT TGC CAT CAT TGG CT-3 and BDNF-R 5-CGT GTA CAA GTC TGC GTC CT-3. Amplification of the 176 bp polymorphic COMT fragment used the primers COMT-F 5-TCA CCA TCG AGA TCA ACC CC-3 and COMT-R 5-GAA CGT GGT GTG AAC ACC TG-3. Polymerase chain reaction (PCR) was conducted using $10 \mathrm{X}$ Taq buffer $(2.5 \mathrm{~L} \mu \mathrm{L})$, Taq polymerase $(0.125 \mu \mathrm{L})$, dNTPs $(5 \mathrm{nmol})$, primers (10 pmol each), Q solution $(5 \mu \mathrm{L})$, and DNA (100 ng) made up to $25 \mu \mathrm{L}$ with $\mathrm{dH}_{2} \mathrm{O}$. The PCR conditions consisted of denaturation at $95^{\circ} \mathrm{C}$ for $15 \mathrm{~min}, 30$ cycles on a ThermoCycler (involving denaturation at $94^{\circ} \mathrm{C}$ for $30 \mathrm{~s}$, annealing at $60^{\circ} \mathrm{C}$ for $30 \mathrm{~s}$, and extension at $72^{\circ} \mathrm{C}$ for $30 \mathrm{~s}$ ) and a final extension at $72^{\circ} \mathrm{C}$.

\section{Enzyme Digestion}

For BDNF, PCR product $(6.5 \mu \mathrm{L})$ was incubated with Pm1l at $37^{\circ} \mathrm{C}$ overnight. For COMT, PCR product $(8 \mu \mathrm{L})$ was incubated with $\mathrm{N} 1 \mathrm{aIII}$ at $37^{\circ} \mathrm{C}$ for $1 \mathrm{~h}$. The digestion products were analyzed 
using a high-resolution agarose gel (4\%) with a Quick Load 100 bp ladder (BioLabs) and a GelPilot Loading Dye (QIAGEN). After immersion in an ethidium bromide solution for $10 \mathrm{~min}$, DNA was visualized under ultraviolet light.

\section{Genotyping}

For $B D N F$, enzyme digestion resulted in a 113 bp fragment for the met ${ }^{66}$ allele, which was cut into 78 and 35 bp fragments for the val ${ }^{66}$ allele. For COMT, digestion resulted in bands of 82, 54 and $41 \mathrm{bp}$ for the val ${ }^{158}$ allele and the $82 \mathrm{bp}$ fragment was cut into 64 and 18 bp fragments for the met ${ }^{158}$ allele. This was as described by Erickson et al. (2008).

\section{Memory Measurements}

Familiarity and recall performance were assessed using two subtests from the Wechsler Memory Scale - Third Edition (WMS-III; Wechsler, 1997b). These subtests were the Faces and Family pictures tasks, each of which tap into visual memory. In the Faces subtest, participants were presented with 24 images of faces that they were requested to remember. The faces were presented serially for $2 \mathrm{~s}$ each. Immediately after being presented with this list, participants were shown 48 faces, half of which they had just seen and the rest of which were novel. For each of these, participants were required to make a judgment as to whether or not they had previously been shown it. Raw Faces scores were converted into percentage correct for each participant.

In the Family Pictures task, participants were first introduced to images of a fictional family consisting of seven members. They were then presented with four scenes in turn, shown for $10 \mathrm{~s}$ each. Within each of these scenes, up to four members of the fictional family appear engaged in various activities in unique spatial locations. Immediately subsequent to the viewing of these, participants were asked set questions that assessed their memory of the scenes. These questions related to the activities and locations of each character. Unlike the Faces subtest, the Family Pictures subtest necessitates recall, with contextualized details of the scenes being retrieved from memory. Raw Family Pictures scores were converted into percentage correct for each participant.

\section{Data Analysis Data Preparation}

Observed $B D N F$ genotypes did not differ significantly from those predicted by Hardy Weinberg equilibrium $\left(\chi^{2}=0.849\right.$, $p>0.05)$. Of the 100 participants, $53(53.0 \%)$ were val $(\mathrm{G})$ homozygotes, $10(10.0 \%)$ were met (A) homozygotes and 37 $(37.0 \%)$ were heterozygotes (val/met; G/A). BDNF genotypes were dichotomised into val homozygotes and met allele carriers for analysis. While research would ideally distinguish between the $B D N F \mathrm{val} / \mathrm{met}$ and met/met genotypes, this is often not practical due to the rarity of met homozygotes and low sample sizes. Consequently, numerous previous studies have combined heterozygotes and met homozygotes in this manner (e.g., Pezawas et al., 2004; Erickson et al., 2008), still detecting significant differences.

For similar reasons, COMT genotypes were dichotomised into met homozygotes and val allele carriers. A number of prior cognitive studies have found only the COMT met homozygotes to significantly differ from the other genotypes, supporting the decision of grouping the heterozygotes and val homozygotes together (e.g., Malhotra et al., 2002; Tsai et al., 2003). COMT genotypes in the present study did not differ significantly from those predicted by Hardy Weinberg equilibrium $\left(\chi^{2}=0.998\right.$, $p>0.05)$. Of the 100 participants, $27(27.0 \%)$ were val (G) homozygotes, $28(28.0 \%)$ were met (A) homozygotes and 45 (45.0\%) were heterozygotes (val/met; G/A).

\section{Statistical Analyses}

A MANOVA was conducted on the Family Pictures (recall) scores and Faces (recognition) scores, with BDNF genotype (val/val and met allele) and COMT genotype (val allele and met/met) as the between-subjects independent variables.

Mean recall and recognition scores for BDNF and COMT genotypes are shown in Table $\mathbf{1 .}$

\section{Results}

Results of the MANOVA are shown in Table 2. The MANOVA revealed a significant main effect of $B D N F$ genotype on recall performance $\left[F_{(1,96)}=6.204, p=0.014\right]$. This main effect is shown in Figure 1. On average, $B D N F$ val homozygotes $(M=79.3, \mathrm{SE}=2.10)$ attained significantly higher recall scores than met allele carriers $(M=72.0, \mathrm{SE}=2.06)$.

A two-way interaction between $B D N F$ and COMT genotype on recall scores was approaching significance $\left[F_{(1,96)}=3.864\right.$, $p=0.052]$. It should be noted that neither this interaction trend nor the main effect of $B D N F$ on recall appear to have been driven by influential outliers. Data screening results were not

TABLE 1 | Mean recall and recognition scores for brain-derived neurotrophic factor (BDNF) and catechol-O-methyltransferase (COMT) genotypes.

\begin{tabular}{|c|c|c|c|c|c|}
\hline Form of memory & BDNF & COMT & Mean & SE & $N$ \\
\hline \multirow[t]{9}{*}{ Recall } & Val/Nal & Val allele & 76.8 & 2.08 & 40 \\
\hline & & Met/Met & 81.8 & 3.65 & 13 \\
\hline & & Total & 79.3 & 2.10 & 53 \\
\hline & Met allele & Val allele & 75.3 & 2.32 & 32 \\
\hline & & Met/Met & 68.8 & 3.40 & 15 \\
\hline & & Total & 72.0 & 2.06 & 47 \\
\hline & Total & Val allele & 76.1 & 1.56 & 72 \\
\hline & & Met/Met & 75.3 & 2.49 & 28 \\
\hline & & Total & 75.8 & 1.34 & 100 \\
\hline \multirow[t]{9}{*}{ Recognition } & Val/Nal & Val allele & 79.1 & 1.71 & 40 \\
\hline & & Met/Met & 81.1 & 3.01 & 13 \\
\hline & & Total & 80.1 & 1.73 & 53 \\
\hline & Met allele & Val allele & 78.8 & 1.92 & 32 \\
\hline & & Met/Met & 82.6 & 2.80 & 15 \\
\hline & & Total & 80.7 & 1.70 & 47 \\
\hline & Total & Val allele & 78.9 & 1.29 & 72 \\
\hline & & Met/Met & 81.9 & 2.05 & 28 \\
\hline & & Total & 79.8 & 1.08 & 100 \\
\hline
\end{tabular}


TABLE 2 | MANOVA for recall (Family Pictures) and recognition (Faces) scores with BDNF genotype and COMT genotype as the between-subjects variables.

\begin{tabular}{lllll}
\hline Source & & $\boldsymbol{F}$ & $\mathbf{d f}$ & $\boldsymbol{P}$ \\
\hline BDNF genotype & Recall & $6.204^{*}$ & 1 & 0.014 \\
& Recognition & 0.068 & 1 & 0.795 \\
COMT genotype & Recall & 0.068 & 1 & 0.795 \\
& Recognition & 1.477 & 1 & 0.227 \\
BDNF* COMT & Recall & 3.864 & 1 & 0.052 \\
Error & Recognition & 0.143 & 1 & 0.706 \\
\hline
\end{tabular}

${ }^{*} p<0.05$.

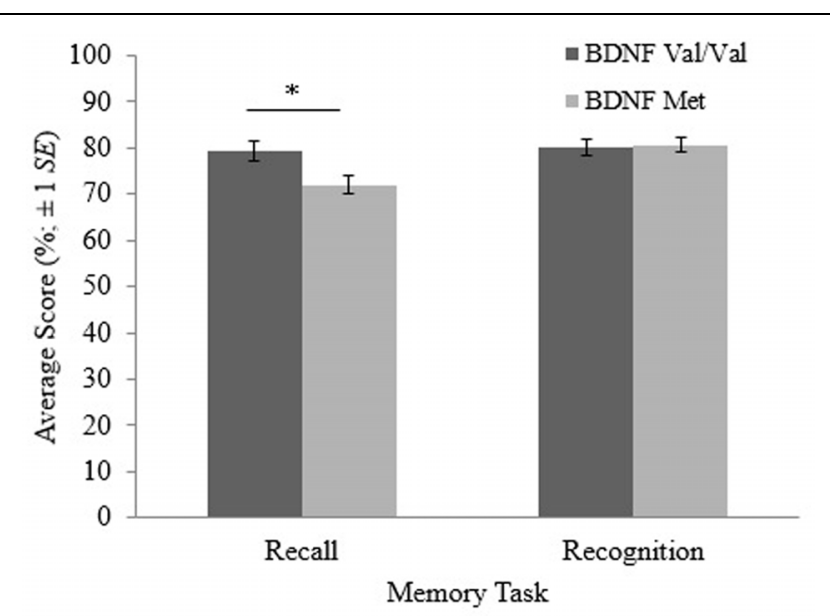

FIGURE 1 | Recall and recognition scores for participants with the brain-derived neurotrophic factor (BDNF) val/val genotype and participants with at least one copy of the BDNF met allele. The error bars are based on \pm 1 SE. ${ }^{*} p<0.05$.

consistent with the presence of influential outliers and ShapiroWilk tests indicate recall scores were sufficiently normally distributed for each BDNF and COMT genotype combination $(p>0.05)$.

No other effects or interactions were significant for recall or recognition.

\section{Discussion}

Support was found for the hypothesis that the BDNF val ${ }^{66}$ met polymorphism would differentially affect recall and familiaritybased recognition. As predicted, there was a main effect of $B D N F$ genotype for recall scores, with val homozygotes significantly outperforming those with a copy of the met allele. In contrast, there was no effect of $B D N F$ genotype on recognition scores. The superior performance of val homozygotes on the recall task replicates previous studies that have assessed hippocampaldependent memory (e.g., Egan et al., 2003; Hariri et al., 2003). Similarly, the lack of effect on familiarity-based recognition reproduces the null effects reported by van Wingen et al. (2010). The differential effect of the BDNF polymorphism on recall and recognition suggests that $B D N F$ is less influential on extrahippocampal structures and processes than it is on those of the hippocampus. This interpretation is consistent with research showing the anatomical and physiological effects of BDNF to be particularly salient in the hippocampus (e.g., Hofer et al., 1990), as well as Hariri et al. (2003) demonstration of BDNF genotype having a hippocampal-specific impact on activation levels. Consequently, the results from the present study may help explain some of the inconsistencies in the existing literature (see Mandelman and Grigorenko, 2012, and Kambeitz et al., 2012 for recent meta-analyses), in that BDNF is unlikely to be implicated in memory in studies where memory is assessed solely on familiarity judgments.

The differential effect on recall and recognition found in the present study has implications for theories of memory, particularly that of Aggleton and Brown (1999). Aggleton and Brown's distinction between recall and familiarity-based recognition has been criticized on the grounds that the importance of recollection in familiarity-based recognition is widely acknowledged, with the overlap between recall and familiarity-based recognition rendering a neural dissociation between these forms of memory invalid (e.g., Mayes et al., 1999). The results of the present study suggest that the difference between recall and recognition is sufficient to have practical consequences for research, as well as possible clinical applications. A distinction between recall and familiarity-based recognition should be considered by researchers investigating the genetics and neural processes involved in memory.

The hypothesis that the COMT val ${ }^{158}$ met genotype would differentially affect recall and recognition performance was not supported in the present study. COMT genotype affected neither recall nor recognition. This is inconsistent with previous studies that have found COMT genotype to have consequences for memory. Research by de Frias et al. (2004) reported that the COMT met allele was beneficial for recall performance, while not affecting recognition. The failure of the present study to replicate this result may be a consequence of differences between the participant samples. de Frias et al. (2004) research sample consisted of older participants, whereas the present study examined the performance of young adults. Furthermore, de Frias et al. (2004) study only involved male participants. Research indicates that the impacts of the COMT polymorphism on cognition can vary with age (e.g., Nagel et al., 2008), and that sex differences might be present (e.g., O'Hara et al., 2006). It should also be noted that meta-analyses (e.g., Barnett et al., 2008) suggest the effects of COMT on memory and other forms of cognition may not be as large as initially thought. Furthermore, other genetic variants affecting the dopaminergic system, such as the dopamine receptor D1 (DRD1) and D2 (DRD2) SNPs, should ideally be included in studies looking at the effects of COMT. When studied in isolation the effects of a single polymorphism on memory may be obscured (Gosso et al., 2008).

While we found a trend toward BDNF and COMT genotypes interacting to affect recall, this did not reach significance. It is possible that our study lacked the statistical power necessary to detect an interaction effect, due to having insufficient participants with certain BDNF and COMT genotypic combinations. While 
there is pre-existing evidence that $B D N F$ genotypes influence levels of LTP induction (Thompson et al., 2013) and may interact with COMT genotypes in doing so (Witte et al., 2012), an effect on this brain-based phenotype may not necessarily result in a robust cognitive phenotype. While Stuart et al. (2014) did detect a significant interaction between $B D N F$ and COMT on immediate auditory recall in older adults, their sample was larger and the effect size modest. Neurophysiological measures may be a more immediate reflection of the neurobiological effects of genes than more distal behavioral measures, as performance on behavioral tasks can be swayed by a multitude of additional factors including motivation, strategy use and attitude to assessment (Goldberg and Weinberger, 2004). Consistent with this, Kambeitz et al. (2012) found that the BDNF polymorphism has a weaker effect on memory performance than it does on hippocampal physiology.

Further studies replicating aspects of the present study would be constructive. The present study had several limitations, some of which were consequences of its small sample size. Due to having a limited number of participants of each genotype for each polymorphism, some genotypes were combined. As a result, this study was not capable of investigating the dosage effects that previous studies have reported to be evident across the three genotypes that result from each polymorphism (e.g., Egan et al., 2001; Beste et al., 2010; Wang et al., 2014). A study with a larger sample size would allow research into additional variables that could potentially influence the effects of these polymorphisms on memory. These variables include age, gender and general intelligence, as well as further genes (e.g., DRD1 and DRD2).

There are also limitations associated with the use of the Faces and Family Pictures tasks from the WMS-III, tasks which have not been included in a more recent edition of the scale

\section{References}

Aggleton, J. P., and Brown, M. W. (1999). Episodic memory, amnesia, and the hippocampal-anterior thalamic axis. Behav. Brain Sci. 22, 425-489. doi: $10.1017 /$ S0140525X99002034

Barnett, J. H., Scoriels, L., and Munafò, M. R. (2008). Meta-analysis of the cognitive effects of the catechol-O-methyltransferase gene val158/108met polymorphism. Biol. Psychiatry 64, 137-144. doi: 10.1016/j.biopsych.2008.01.005

Beste, C., Baune, B. T., Domschke, K., Falkenstein, M., and Konrad, C. (2010). Paradoxical association of the brain-derived-neurotrophic-factor val66met genotype with response inhibition. Neuroscience 166, 178-184. doi: 10.1016/j.neuroscience.2009.12.022

Bilder, R. M., Volavka, J., Czobor, P., Malhotra, A. K., Kennedy, J. L., Ni, X., et al. (2002). Neurocognitive correlates of the COMT val158met polymorphism in chronic schizophrenia. Biol. Psychiatry 52, 701-707. doi: 10.1016/S00063223(02)01416-6

Bliss, T. V. P., and Collingridge, G. L. (1993). A synaptic model of memory: long-term potentiation in the hippocampus. Nature 361, 31-39. doi: 10.1038/361031a0

Brozoski, T., Brown, R. M., Rosvold, H. E., and Goldman, P. S. (1979). Cognitive deficit caused by regional depletion of dopamine in prefrontal cortex of rhesus monkey. Science 205, 929-931. doi: 10.1126/science. 112679

Bussey, T. J., Muir, J. L., and Aggleton, J. P. (1999). Functionally dissociating aspects of event memory: the effects of combined perirhinal and postrhinal cortex lesions on object and place memory in the rat. J. Neurosci. 19, 495-502.

Cai, J. X., and Arnsten, A. F. T. (1997). Dose-dependent effects of the dopamine D1 receptor agonists A77636 or SFK81297 on spatial working
(WMS-IV; Wechsler, 2009) due in part to issues associated with their scoring systems (Pearson Clinical Assessment, 2009). In the present study, the Faces and Family Pictures tasks were scored according to the WMS-III Administration and Scoring Manual (Wechsler, 1997a). Many of our participants lost marks on the Family Pictures task due to misidentifying characters with similar appearances. As a consequence of these errors, they could not receive marks for any correct recall of the location and activity associated with that misidentified character. Therefore visual discrimination and recognition abilities also played a role in determining the scores participants received in the Family Pictures task, rather than it being a pure test of recalled associations. This is less than ideal and future research may look to replicate the present result with a more valid recall measure.

The present study contributes to our understanding of the genetic influences on normal memory variation in healthy young adults. It replicates and builds upon previous findings in demonstrating that the $B D N F$ val allele benefits recall performance while not influencing familiarity-based recognition performance. The role of $B D N F$ in the structure and function of the hippocampus in particular is consistent with the effect of the BDNF polymorphism being specific to hippocampaldependent forms of memory such as recall. This differential effect on recall and recognition substantiates the legitimacy and desirability of distinguishing between these forms of memory when investigating the genetic underpinnings of memory. Combining subscale scores such as is usually done in the WMS will likely obscure the effects of the BDNF polymorphism. Sensitivity may be lost when collapsing across different cognitive phenotypes, contributing to inconsistencies in the literature.

memory in aged monkeys. J. Pharmacol. Exp. Ther. 283, 183-189. doi: 10.1016/j.neuropharm.2012.10.029

Chen, Z. Y., Patel, P. D., Sant, G., Meng, C. X., Teng, K. K., Hempstead, B. L., et al. (2004). Variant brain-derived neurotrophic factor (BDNF) (Met66) alters the intracellular trafficking and activity-dependent secretion of wildtype BDNF in neurosecretory cells and cortical neurons. J. Neurosci. 24, 4401-4411. doi: 10.1523/JNEUROSCI.0348-04.2004

Cooke, S. F., and Bliss, T. V. P. (2006). Plasticity in the human central nervous system. Brain 129, 1659-1673. doi: 10.1093/brain/awl082

Cunha, C., Brambilla, R., and Thomas, K. L. (2010). A simple role for BDNF in learning and memory? Front. Mol. Neurosci. 3:1. doi: 10.3389/neuro.02.001.2010

Davidson, P. S. R., Troyer, A. K., and Moscovitch, M. (2006). Frontal lobe contributions to recognition and recall: linking basic research with clinical evaluation and remediation. J. Int. Neuropsychol. Soc. 12, 210-223. doi: 10.1017/S1355617706060334

de Frias, C. M., Annerbrink, K., Westberg, L., Eriksson, E., Adolfsson, R., and Nilsson, L.-G. (2004). COMT gene polymorphism is associated with declarative memory in adulthood and old age. Behav. Genet. 34, 533-539. doi: 10.1023/B:BEGE.0000038491.06972.8c

Duva, C. A., Floresco, S. B., Wunderlich, G. P., Lao, T. L., Pinel, J. P. J., and Phillips, A. G. (1997). Disruption of spatial but not object-recognition memory by neurotoxic lesions of the dorsal hippocampus in rats. Behav. Neurosci. 111, 1184-1196. doi: 10.1037/0735-7044.111.6.1184

Egan, M. F., Goldberg, T. E., Kolachana, B. S., Callicott, J. H., Mazzanti, C. M., Straub, R. E., et al. (2001). Effect of COMT Val108/158Met genotype on frontal lobe function and risk for schizophrenia. Proc. Natl. Acad. Sci. U.S.A. 98, 6917-6922. doi: 10.1073/pnas.111134598 
Egan, M. F., Kojima, M., Callicott, J. H., Goldberg, T. E., Kolachana, B. S., Bertolino, A., et al. (2003). The BDNF val66met polymorphism affects activitydependent secretion of BDNF and human memory and hippocampal function. Cell 112, 257-269. doi: 10.1016/S0092-8674(03)00035-7

Enoch, M.-A., Waheed, J. F., Harris, C. R., Albaugh, B., and Goldman, D. (2009). COMT val158met and cognition: main effects and interaction with educational attainment. Genes Brain Behav. 8, 36-42. doi: 10.1111/j.1601183X.2008.00441.x

Erickson, K. I., Kim, J. S., Suever, B. L., Voss, M. W., Francis, B. M., and Kramer, A. F. (2008). Genetic contributions to age-related decline in executive function: a 10-year longitudinal study of COMT and BDNF polymorphisms. Front. Hum. Neurosci. 2:11. doi: 10.3389/neuro.09.011.2008

Fernández, G., and Tendolkar, I. (2001). Integrated brain activity in medial temporal and prefrontal area predicts subsequent memory performance: human declarative memory formation at the system level. Brain Res. Bull. 55, 1-9. doi: 10.1016/S0361-9230(01)00494-4

Goldberg, T. E., and Weinberger, D. R. (2004). Genes and the parsing of cognitive processes. Trends Cogn. Sci. 8, 325-335. doi: 10.1016/j.tics.2004.05.011

Gosso, M. F., de Geus, E. J. C., Polderman, T. J. C., Boomsma, D. I., Heutink, P., and Posthuma, D. (2008). Catechol O-methyltransferase and dopamine D2 receptor gene polymorphisms: evidence of positive heterosis and gene-gene interaction on working memory functioning. Eur. J. Hum. Genet. 16, 1075-1082. doi: 10.1038/ejhg.2008.57

Hajek, T., Kopecek, M., and Höschl, C. (2012). Reduced hippocampal volumes in healthy carriers of brain-derived neurotrophic factor Val66Met polymorphism: meta-analysis. World J. Biol. Psychiatry 13, 178-187. doi: $10.3109 / 15622975.2011 .580005$

Hansell, N. K., James, M. R., Duffy, D. L., Birley, A. J., Luciano, M., Geffen, G. M., et al. (2007). Effect of the BDNF v166m polymorphism on working memory in healthy adolescents. Genes Brain Behav. 6, 260-268. doi: 10.1111/j.1601183X.2006.00254.x

Hariri, A. R., Goldberg, T. E., Mattay, V. S., Kolachana, B. S., Callicott, J. H., Egan, M. F., et al. (2003). Brain-derived neurotrophic factor val66met polymorphism affects human memory-related hippocampal activity and predicts memory performance. J. Neurosci. 23, 6690-6694.

Harrisberger, F., Spalek, K., Smieskova, R., Schmidt, A., Coynel, D., Milnik, A., et al. (2014). The association of the BDNF val66met polymorphism and the hippocampal volumes in healthy humans: a joint meta-analysis of published and new data. Neurosci. Biobehav. Rev. 42, 267-278. doi: 10.1016/j.neubiorev.2014.03.011

Hofer, M., Pagliusi, S. R., Hohn, A., Leibrock, J., and Barde, Y. A. (1990). Regional distribution of brain-derived neurotrophic factor mRNA in the adult mouse brain. EMBO J. 9, 2459-2464.

Honea, R., Verchinski, B. A., Pezawas, L., Kolachana, B. S., Callicott, J. H., Mattay, V. S., et al. (2009). Impact of interacting functional variants in COMT on regional gray matter volume in human brain. Neuroimage 45, 44-51. doi: 10.1016/j.neuroimage.2008.10.064

Huang, E. J., and Reichardt, L. F. (2003). Trk receptors: roles in neuronal signal transduction. Annu. Rev. Biochem. 72, 609-642. doi: 10.1146/annurev.biochem.72.121801.161629

Jacobsen, L. M., Eriksen, G. S., Pedersen, L. M., and Gjerstad, J. (2010). Catechol-O-methyltransferase (COMT) inhibition reduces spinal nociceptive activity. Neurosci. Lett. 473, 212-215. doi: 10.1016/j.neulet.2010. 02.049

Jasper, M., Dideberg, V., Bours, V., Maquet, P., and Collette, F. (2015). Modulating effect of COMT val158met polymorphism on interference resolution during a working memory task. Brain Cogn. 95, 7-18. doi: 10.1016/j.bandc.2015.01.013

Kafkas, A., and Montaldi, D. (2012). Familiarity and recollection produce distinct eye movement, pupil and medial temporal lobe responses when memory strength is matched. Neuropsychologia 50, 3080-3093. doi: 10.1016/j.neuropsychologia.2012.08.001

Kambeitz, J. P., Bhattacharyya, S., Kambeitz-Ilankovic, L. M., Valli, I., Collier, D. A., and McGuire, P. (2012). Effect of BDNF val66met polymorphism on declarative memory and its neural substrate: a meta-analysis. Neurosci. Biobehav. Rev. 36, 2165-2177. doi: 10.1016/j.neubiorev.2012.07.002

Kirk, I. J., Clapp, W. C., Fairhall, S. L., Hamm, J. P., Hornsey, E., and Jackson, G. D. (2004). Neural substrates of recognition memory: a 3T fMRI study. Am. J. Psychol. 56, 121-121.
Knowlton, B. J. (1999). Recall, recognition, and the medial temporal lobes. Behav. Brain Sci. 22, 455-456. doi: 10.1017/S0140525X99332039

Lachman, H. M., Papolos, D. F., Saito, T., Yu, Y. M., Szumlanski, C. L., and Weinshilboum, R. M. (1996). Human catechol-O-methyltransferase pharmacogenetics: description of a functional polymorphism and its potential application to neuropsychiatric disorders. Pharmacogenetics 6, 243-250. doi: 10.1097/00008571-199606000-00007

Lamb, Y. N., McKay, N. S., Thompson, C. S., Hamm, J. P., Waldie, K. E., and Kirk, I. J. (2014). Brain-derived neurotrophic factor val66met polymorphism, human memory, and synaptic neuroplasticity. Cogn. Sci. 6, 97-108. doi: $10.1002 /$ wcs. 1334

Lessmann, V., Gottmann, K., and Malcangio, M. (2003). Neurotrophin secretion: current facts and future prospects. Prog. Neurobiol. 69, 341-374. doi: 10.1016/S0301-0082(03)00019-4

Lotta, T., Vidgren, J., Tilgmann, C., Ulmanen, I., Melén, K., Julkunen, I., et al. (1995). Kinetics of human soluble and membrane-bound catechol O-methyltransferase: a revised mechanism and description of the thermolabile variant of the enzyme. Biochemistry 34, 4202-4210. doi: 10.1021/bi00013a008

Malhotra, A. K., Kestler, L. J., Mazzanti, C., Bates, J. A., Goldberg, T., and Goldman, D. (2002). A functional polymorphism in the COMT gene and performance on a test of prefrontal cognition. Am. J. Psychiatry 159, 652-654. doi: 10.1176/appi.ajp.159.4.652

Mandelman, S. D., and Grigorenko, E. L. (2012). BDNF val66met and cognition: all, none, or some? A meta-analysis of the genetic association. Genes Brain Behav. 11, 127-136. doi: 10.1111/j.1601-183X.2011.00738.x

Mandler, G. (1980). Recognizing: the judgment of previous occurrence. Psychol. Rev. 87, 252-271. doi: 10.1037/0033-295X.87.3.252

Mandler, G. (2008). Familiarity breeds attempts: a critical review of dual-process theories of recognition. Perspect. Psychol. Sci. 3, 390-399. doi: 10.1111/j.17456924.2008.00087.x

Mattay, V. S., Goldberg, T. E., Fera, F., Hariri, A. R., Tessitore, A., Egan, M. F., et al. (2003). Catechol O-methyltransferase val158-met genotype and individual variation in the brain response to amphetamine. Proc. Natl. Acad. Sci. U.S.A. 100, 6186-6191. doi: 10.1073/pnas.0931309100

Mayes, A. R., van Eijk, R., Gooding, P. A., Isaac, C. L., and Holdstock, J. S. (1999). What are the functional deficits produced by hippocampal and perirhinal cortex lesions? Behav. Brain Sci. 22, 460-461. doi: 10.1017/S0140525X99372034

McIntosh, A. M., Baig, B. J., Hall, J., Job, D., Whalley, H. C., Lymer, G. K. S., et al. (2007). Relationship of catechol-O-methyltransferase variants of brain structure and function in a population at high risk of psychosis. Biol. Psychiatry 61, 1127-1134. doi: 10.1016/j.biopsych.2006.05.020

Meunier, M., Bachevalier, J., Mishkin, M., and Murray, E. A. (1993). Effects on visual recognition of combined and separate ablations of the entorhinal and perirhinal cortex in rhesus monkeys. J. Neurosci. 12, 5418-5432.

Meyer-Lindenberg, A., Nichols, T., Callicott, J. H., Ding, J., Kolachana, B., Buckholtz, J., et al. (2006). Impact of the complex genetic variation in COMT on human brain function. Mol. Psychiatry 11, 867-877. doi: 10.1038/sj.mp. 4001860

Miller, S. A., Dykes, D. D., and Polesky, H. F. (1988). A simple salting out procedure for extracting DNA from human nucleated cells. Nucleic Acids Res. 16, 1215. doi: 10.1093/nar/16.3.1215

Mitaki, S., Isomura, M., Maniwa, K., Yamasaki, M., Nagai, A., Nabika, T., et al. (2013). Impact of five SNPs in dopamine-related genes on executive function. Acta Neurol. Scand. 127, 70-76. doi: 10.1111/j.1600-0404.2012. 01673.x

Mohapel, P., Frielingsdorf, H., Häggblad, J., Zachrisson, O., and Brundin, P. (2005). Platelet-derived growth factor (PDGF-BB) and brain-derived neurotrophic factor (BDNF) induce striatal neurogenesis in adult rats with 6-hyrdroxydopamine lesions. Neuroscience 132, 767-776. doi: 10.1016/j.neuroscience.2004.11.056

Molendijk, M. L., Bus, B. A., Spinhoven, P., Kaimatzoglou, A., Voshaar, R. C. O., Penninx, B. W., et al. (2012). A systematic review and meta-analysis on the association between BDNF val66met and hippocampal volume - A genuine effect or a winners curse? Am. J. Med. Genet. B 159B, 731-740. doi: 10.1002/ajmg.b.32078

Morris, R. G., Garrud, P., Rawlins, J. N. P., and O'Keefe, J. (1982). Place navigation impaired in rats with hippocampal lesions. Nature 297, 681-683. doi: $10.1038 / 297681 \mathrm{a} 0$ 
Murer, M. G., Yan, Q., and Raisman-Vozari, R. (2001). Brain-derived neurotrophic factor in the control human brain, and in Alzheimer's disease and Parkinson's disease. Prog. Neurobiol. 63, 71-124. doi: 10.1016/S0301-0082(00)00014-9

Nagel, I. E., Chicherio, C., Li, S.-C., von Oertzen, T., Sander, T., Villringer, A., et al. (2008). Human aging magnifies genetic effects on executive functioning and working memory. Front. Hum. Neurosci. 2:1. doi: 10.3389/neuro.09.001.2008

Nieoullon, A. (2002). Dopamine and regulation of cognition and attention. Prog. Neurobiol. 67, 53-83. doi: 10.1016/S0301-0082(02)00011-4

Nilsson, L.-G. (2000). "Can genes teach us anything about memory?" in Proceeding of the Memory, Consciousness, and the Brain: The Tallinn Conference, ed. E. Tulving (Philadelphia, PA: Psychology Press), 28-37.

Nishita, D. M., Jack, L. M., McElroy, M., McClure, J. B., Richards, J., Swan, G. E., et al. (2009). Clinical trial participant characteristics and saliva and DNA metrics. BMC Med. Res. Methodol. 9:71. doi: 10.1186/1471-2288-9-71

O’Hara, R., Miller, E., Liao, C. P., Way, N., Lin, X., and Hallmayer, J. (2006). COMT genotype, gender and cognition in community-dwelling, older adults. Neurosci. Lett. 409, 205-209. doi: 10.1016/j.neulet.2006.09.047

Panja, D., and Bramham, C. R. (2014). BDNF mechanisms in lateLTP formation and synthesis. Neuropharmacology 76, 664-676. doi: 10.1016/j.neuropharm.2013.06.024

Parker, A. (1999). Memory systems, frontal cortex, and the hippocampal axis. Behav. Brain Sci. 22, 464-465. doi: 10.1017/S0140525X99412038

Pearson Clinical Assessment. (2009). "WMS-III to WMS-IV: Rationale for Change" PearsonAssessments.com. Available at: http://images.pearsonclinical. com/images/Products/WMS-IV/WMS-RationaleforChange.pdf [accessed November 3, 2014].

Perfect, T. J., Mayes, A. R., Downes, J. J., and Van Eijk, R. (1996). Does context discriminate recollection from familiarity in recognition memory? Q. J. Exp. Psychol. 49A, 797-813. doi: 10.1080/713755644

Pergola, G., Gunturkun, O., Koch, B., Schwarz, M., Daum, I., and Suchan, B. (2012). Recall deficits in stroke patients with thalamic lesions covary with damage to the parvocellular mediodorsal nucleus of the thalamus. Neuropsychologia 50, 2477-2491. doi: 10.1016/j.neuropsychologia.2012.06.019

Pergola, G., Ranft, A., Mathias, K., and Suchan, B. (2013). The role of the thalamic nuclei in recognition memory accompanied by recall during encoding and retrieval: an fMRI study. Neuroimage 74, 195-208. doi: 10.1016/j.neuroimage.2013.02.017

Pezawas, L., Verchinski, B. A., Mattay, V. S., Callicott, J. H., Kolachana, B. S., Straub, R. E., et al. (2004). The brain-derived neurotrophic factor val66met polymorphism and variation in human cortical morphology. J. Neurosci. 24, 10099-10102. doi: 10.1523/JNEUROSCI.2680-04.2004

Poo, M. M. (2001). Neurotrophins as synaptic modulators. Nat. Rev. Neurosci. 2, 24-32. doi: 10.1038/35049004

Raz, N., Rodrigue, K. M., Kennedy, K. M., and Land, S. (2009). Genetic and vascular modifiers of age-sensitive cognitive skills: effects of COMT, BDNF, ApoE and hypertension. Neuropsychology 23, 105-116. doi: 10.1037/a0013487

Ryan, L., Cox, C., Hayes, S. M., and Nadel, L. (2008). Hippocampal activation during episodic and semantic memory retrieval: comparing category production and category cued recall. Neuropsychologia 46, 2109-2121. doi: 10.1016/j.neuropsychologia.2008.02.030

Sairanen, M., Lucas, G., Ernfors, P., Castren, M., and Castren, E. (2005). Brainderived neurotrophic factor and antidepressant drugs have different but coordinated effects on neuronal turnover, proliferation, and survival in the adult dentate gyrus. J. Neurosci. 25, 1089-1094. doi: 10.1523/JNEUROSCI.374104.2005

Schacter, D. L., Alpert, N. M., Savage, C. R., Rauch, S. L., and Albert, M. S. (1996). Conscious recollection and the human hippocampal formation: evidence from positron emission tomography. Proc. Natl. Acad. Sci. U.S.A. 93, 321-325. doi: 10.1073/pnas.93.1.321

Scharfman, H., Goodman, J., Macleod, A., Phani, S., Antonelli, C., and Croll, S. (2005). Increased neurogenesis and the ectopic granule cells after intrahippocampal BDNF infusion in adult rats. Exp. Neurol. 192, 348-356. doi: 10.1016/j.expneurol.2004.11.016
Squire, L. R., Ojemann, J. G., Miezin, F. M., Petersen, S. E., Videen, T. O., and Raichle, M. E. (1992). Activation of the hippocampus in normal humans: a functional anatomical study of memory. Proc. Natl. Acad. Sci. U.S.A. 89, 1837-1841. doi: 10.1073/pnas.89.5.1837

Steele, K., and Rawlins, J. N. P. (1993). The effects of hippocampectomy on performance by rats of a running recognition task using long lists of non-spatial items. Behav. Brain Res. 54, 1-10. doi: 10.1016/0166-4328(93)90043-P

Stuart, K., Summers, M. J., Valenzuela, M. J., and Vickers, J. C. (2014). COMT and BDNF polymorphisms have a limited association with episodic memory performance or engagement in complex cognitive activity in healthy older adults. Neurobiol. Learn. Mem. 110, 1-7. doi: 10.1016/j.nlm.2014.01.013

Thakker-Varia, S., Behnke, J., Doobin, D., Dalal, V., Thakker, K., Khadim, F., et al. (2014). VGF (TLQP-62)-induced neurogenesis targets early phase neural progenitor cells in the adult hippocampus and requires glutamate and BDNF signaling. Stem Cell Res. 12, 762-777. doi: 10.1016/j.scr.2014.03.005

Thompson, C. S., McNair, N. A., Antia, U., Kennedy, K., Shelling, A. N., Russell, B. R., et al. (2013). Brain-derived neurotrophic factor val66met polymorphism influences the magnitude of human long-term potentiation which predicts memory performance. J. Cog. Neurosci. 113, 6690-6694.

Tsai, S.-J., Yu, Y. W.-Y., Chen, T.-J., Chen, J.-Y., Liou, Y. J., Chen, M.-C., et al. (2003). Association study of a functional catechol-O-methyltransferase-gene polymorphism and cognitive function in healthy females. Neurosci. Lett. 338, 123-126. doi: 10.1016/S0304-3940(02)01396-4

van Wingen, G., Rijpkema, M., Franke, B., van Eijndhoven, P., Tendolkar, I., Verkes, R. J., et al. (2010). The brain-derived neurotrophic factor val66met polymorphism affects memory formation and retrieval of biologically salient stimuli. Neuroimage 50, 1212-1218. doi: 10.1016/j.neuroimage.2010.01.058

Wang, C., Zhang, Y., Liu, B., Long, H., Yu, C., and Jiang, T. (2014). Dosage effects of BDNF val66met polymorphism on cortical surface area and functional connectivity. J. Neurosci. 34, 2645-2651. doi: 10.1523/JNEUROSCI.350113.2014

Wechsler, D. (1997a). WMS-III: Administration and Scoring Manual. San Antonio, TX: The Psychological Corporation.

Wechsler, D. (1997b). WMS-III: Wechsler Memory Scale, 3rd Edn. San Antonio, TX: The Psychological Corporation.

Wechsler, D. (2009). WMS-IV: Wechsler Memory Scale, 4th Edn. San Antonio, TX: The Psychological Corporation.

Witte, A. V., Kurten, J., Jansen, S., Schirmacher, A., Brand, E., Sommer, J., et al. (2012). Interaction of BDNF and COMT polymorphisms on pairedassociative stimulation-induced cortical plasticity. J. Neurosci. 32, 4553-4561. doi: 10.1523/JNEUROSCI.6010-11.2012

Xu, T.-X., Sotnikova, T. D., Liang, C., Zang, J., Jung, J. U., Spealman, R. D., et al. (2009). Hyperdopaminergic tone erodes prefrontal long-term potential via a D2 receptor-operated protein phosphatase gate. J. Neurosci. 29, 14086-14099. doi: 10.1523/JNEUROSCI.0974-09.2009

Zahrt, J., Taylor, J. R., Mathew, R. G., and Arnsten, A. F. T. (1997). Supranormal stimulation of D1 dopamine receptors in the rodent prefrontal cortex impairs spatial working memory performance. J. Neurosci. 17, 8528-8535.

Zhou, J., Bradford, H. F., and Stern, G. M. (1994). The response of human and rat fetal ventral mesencephalon in culture to the brain-derived neurotrophic factor treatment. Brain Res. 656, 147-156. doi: 10.1016/0006-8993(94)91376-5 doi: 10.1016/0006-8993(94)91376-5

Conflict of Interest Statement: The authors declare that the research was conducted in the absence of any commercial or financial relationships that could be construed as a potential conflict of interest.

Copyright (c) 2015 Lamb, Thompson, McKay, Waldie and Kirk. This is an open-access article distributed under the terms of the Creative Commons Attribution License (CC BY). The use, distribution or reproduction in other forums is permitted, provided the original author(s) or licensor are credited and that the original publication in this journal is cited, in accordance with accepted academic practice. No use, distribution or reproduction is permitted which does not comply with these terms. 